\title{
Funerary groups of third dynasty queens
}

\section{Mahrous Al-Sanadidi}

\section{Temporary Exhibit Supervisor at the National Museum of Egyptian Civilization, Fustat}

\section{elsanadidy@gmail.com}

\section{Abstract:}

In recent years, many new funerary groups of queens from the Old Kingdom (2649-2134 BC) have been discovered, especially in the cemetery of Saqqara and Abusir, one of the most important cemeteries of the city of Memphis, the capital of the old state. S. Bibi II", and groups in which no text was found referring to the names of their owners, such as: the hierarchical group of Pesius 24 in Abusir, and the hierarchical group called the Pyramid of the West in the cemetery of King "Baby I" south of Saqqara, and some of the funerary groups of queens whose name was not known from Before Nate the First, Nabo Wenet, AnnekAnti, Bahnu, and Miha, in addition to that we know the names of the queens, but we could not determine the locations of their funerary groups, including those of the queens of the Third Dynasty.

Hence, there were many questions that needed answers, including: Is it possible to date the funerary groups of the queens through the architectural elements of the group's components compared to other groups?, and was the architecture of the funerary groups of queens in 
the old state affected by religious or political factors, including the funerary groups of family queens The third?

The research is based on theoretical, descriptive, historical, analytical and practical study.

Key words: queen - third dynasty - ancient state - funeral group

فى السنو ات الأخيرة تم الكثف عن العديد من المجموعات الجنائزية الجديدة لملكات من الدولة

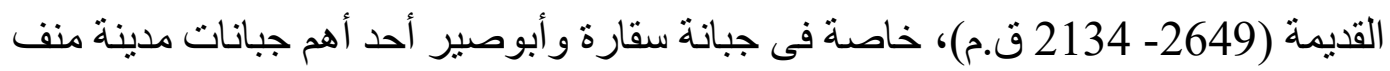
عاصمة الدولة القديمة، وتلك المجمو عات الجنائزية بعضها كان لملكات معروفات الاسم مثل فئل

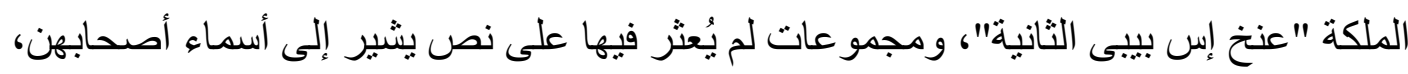

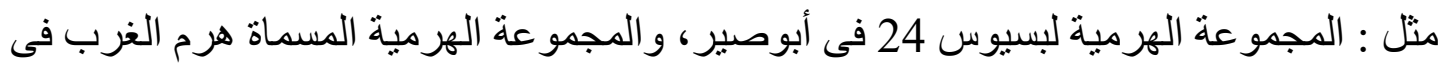

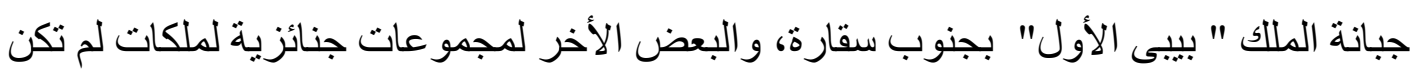

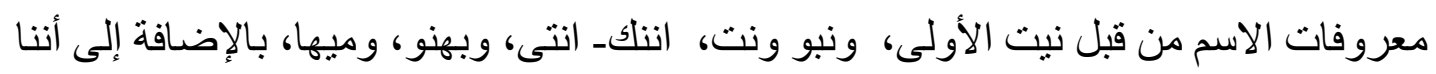

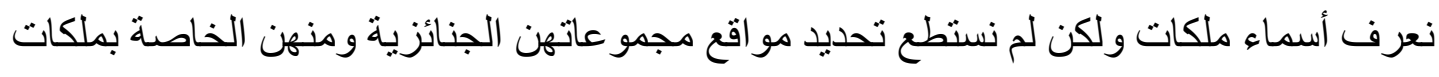

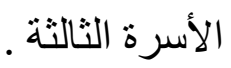

ومن ثم كانت هناك العديد من الأسئلة التى تحتاج لإجابات ومنها: هل من المكن أن نؤرخ

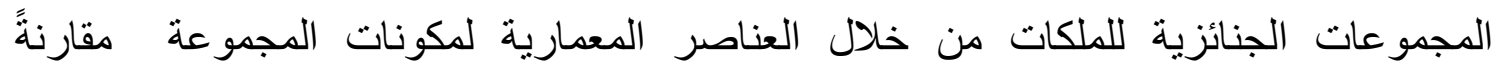
بمجموعات أخرى؟، و هل تأثرت عمارة المجموعات الجنائزية للملكات فى الدولة القديمة بعو امل

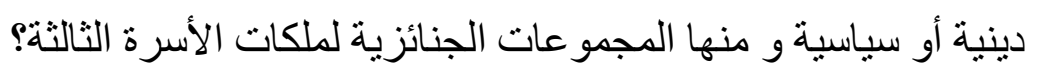
البحث يقوم على الدراسة النظرية و الوصفية و التاريخية و التحليلية و العملية. الكلمات الدالة: ملكةـ أسرة ثالثة ـ دولة قليمة ــ مجموعة جنائزية. تمهي⿻: الأسرة الثالثة [2649 - 2575 ق. م م 
اختلف الدارسون و المؤرخون في ترتيب ملوك الأسرة الثالثة ، وفى كيفية انتقال العرش إلى

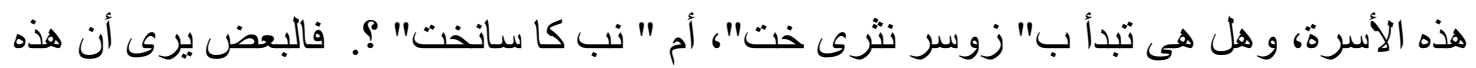

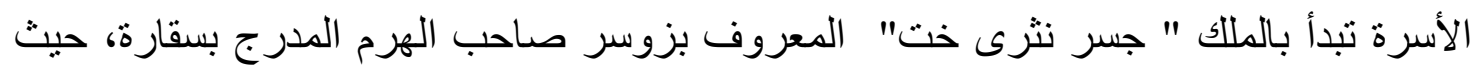
ورد اسمه فى بردية تورين بالمداد الأحمر بين أسماء ملوك الأسرة الثالثة، وذكر كاتب من القرن الثاني عشر ق. م اسمه مع كل من مؤسس الأسرة الخامسة الملك "وسر كاف" ومؤسس الأسرة

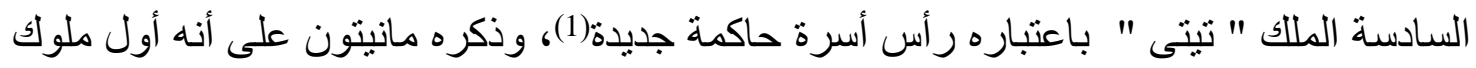
الأسرة الثالثة، وأطلق عليه اسم "تسورثروس" كصاحب أول مجموعة جنائزية بنيت من بنارئ الحجر (2) ويتفق على رضوان مع الرأى القائل : إن الملك" زوسر " هو أول ملوك الأسرة الثالثة ،

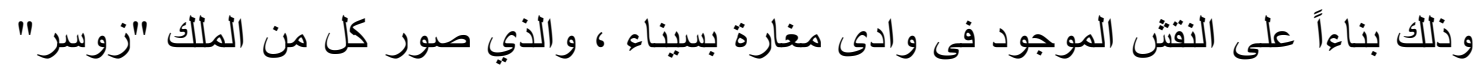
و الملك " سخم خت "، و الملك "سانخت" وهم يقوموا بتأديب البدو، ويظهر من مستوى دقة وجودة النقش الخاص بالملك سانخت أنه أكثر إتقاناً عنه في نقش الملك "زوسر" والملك "سخم

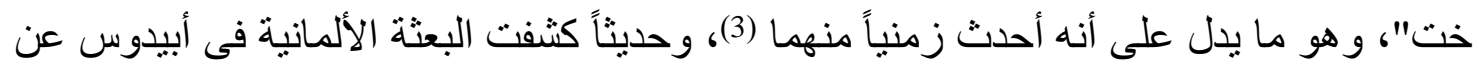
أدلة تثبت أن الملك " زوسر" هو من قام بإجر اءات وطقوس جنازة الملكة "نى ـ ماعت ـ حاب

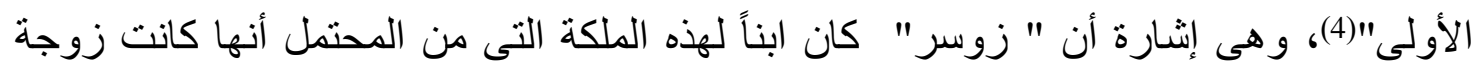

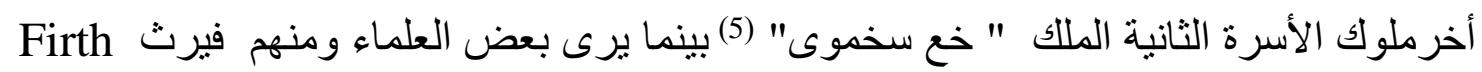

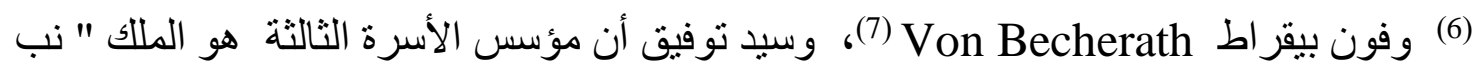
كا سانخت" حيث ذكر اسمه كأول ملوك الأسرة الثالثة فى قائمة أبيدوس وقائمة بردية تورين(8)، وبناءاً على ما تقدم يرى معظم العلماء أن الترتيب المحتمل لملوك هذه الأسرة هو كالتالى : نثرى لهرى

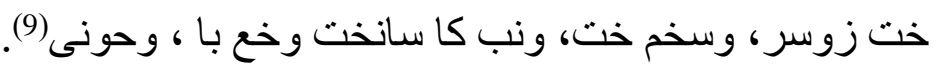
مقدمة عن المجموعات الجنائزية لملكات الأسرة الثالثة:

ما تزال أسماء العديد من الملكات فى الأسرة الثالثة غير معلومة لنا حتى الآن، وما يزال

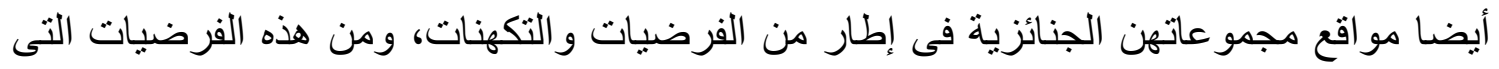

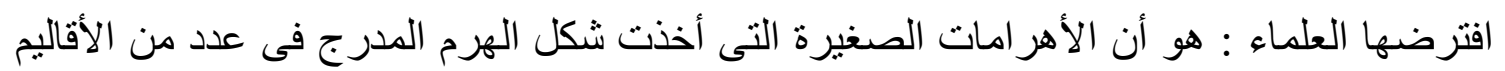
المصرية ترجع للفترة ما بين النصف الثانى من الأسرة الثالثة حتى عهد سنفرو، ومنهم لوير

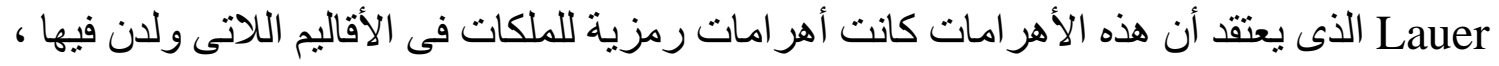

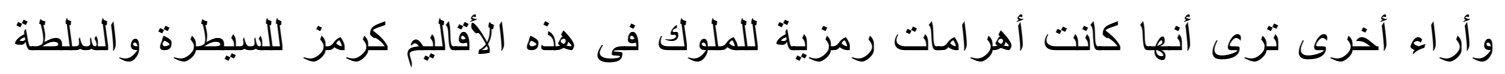

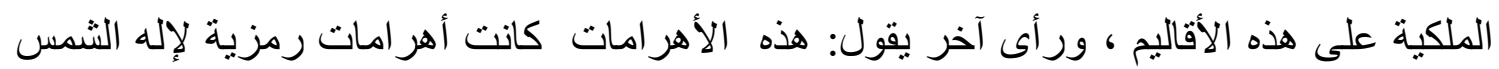

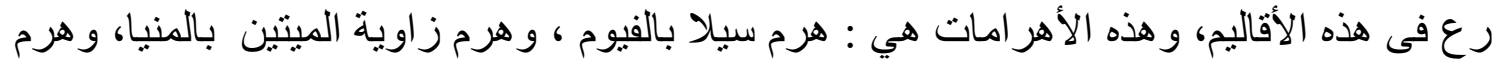


سينكى (نجع الخليفة) جنوب أبيدوس بخمسة كيلو مثرات ، و هرم نقادة ، وهرم كولة (نجع ماماريا)

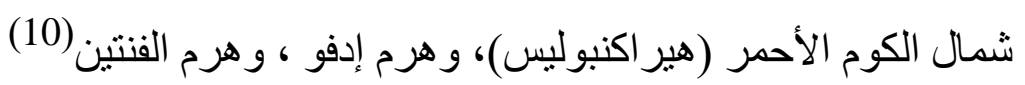
أما بالنسبة لأهم الملكات المعروف لاينا أسماءهن فى الأسرة الثالثة حتى الآن فهن كالتالى:

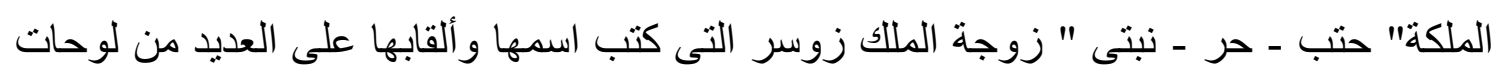

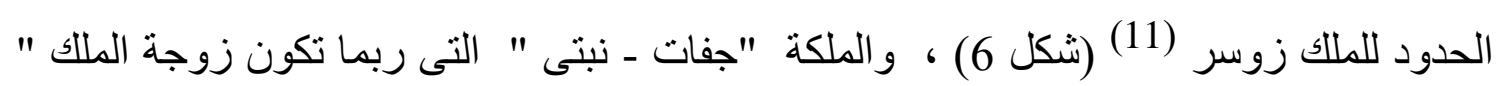
حونى "، والتى كتب اسمها ولقبها على إناء عثر عليه فى الفنتين (12)، والملكة " مرى - إس عنخ الأولى "زوجة الملك " حونى" أخر ملوك الأسرة الثالثة وأم الملك "سنفرو" (13). و أما عن الملكات زوجات الملوك : " سخم خت"، و " نب كا سانخت" ، و " خع با " فلم يكثف عن

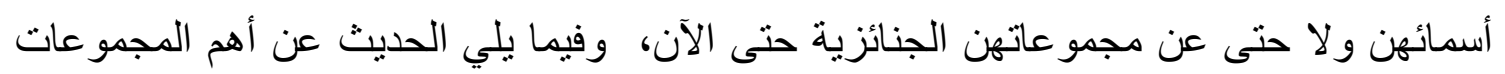

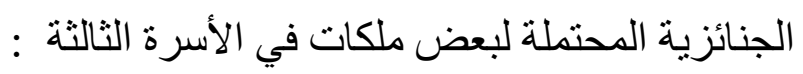

\section{1-1-1 المجموعة الجنائزية للملكة حتب - حر - نبتى (Xtp-Xr -Nbty): 1-1-1-1 من هي الملكة حتب - حر - نبتى؟:}

هى زوجة الملك " زوسر" وربما كانت ابنة الملك " خع سخموى" و الملكة " نى ـ ماعت ـ

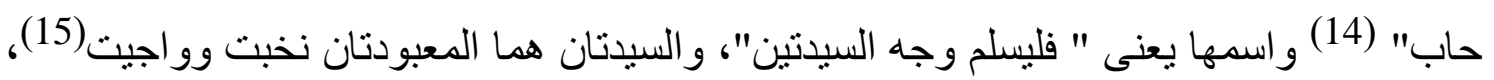
وقد نقش اسمها على العديد من لوحات الحدود للملك زوسر، والتى عثر منها حتى الآن على ما يقرب من أربعين لوحة (16) فى أماكن متفرقة: منها ما عثر عليه فى داخل مجموعة زوسر لهرد الهرمية نفسها (17)، ومنها ما عثر عليه فى عين شمس(18)، ومنها ما عثر عليه فى جبانة الملك تينى شمال شرق الهرم المدرج ، ومنها ما عثرت عليه البعثة البولندية فى موقع حفائر ها الذي يقع غرب الهرم المدرج (19)، وأحدث هذه اللوحات المكتشفة هى اللوحة التى عثرت عليها بعثة جامعة القاهرة بمنطقة سقارة فى أثناء أعمال حفائر ها موسم 2006، و هذه اللوحة كان قد أعيد استخدامها في بناء فوهة بئر مقبرة كبير الثرطة فى عصر الرعامسة " واج مس " (20)، وهذه اللوحة منقوش عليها الاسم " الحورى" لزوسر " نثرى خت" Nüry vt داخل السرخ ، وقد نقش

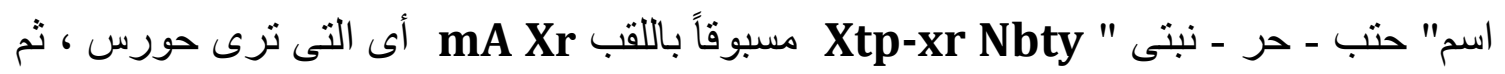

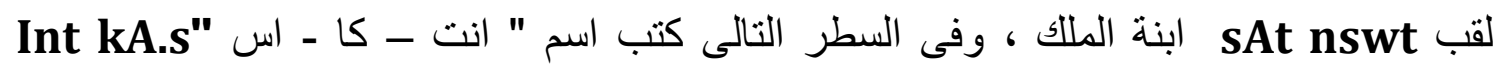


ويسبقها لقب sAt nswt أى ابنة الملك وترى " العجيزى " أن اللقب mA Xr مع " حتب حر- نبتى " هو جزء من اللقب mAAt Xr Sü التى ترى حورس وست ، وهو من الألقاب

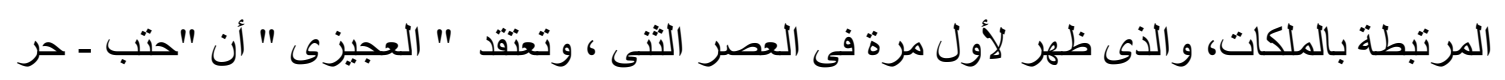

ـ نبتى " ربما كانت ابنة الملك " خع سخموى" والملكة " نى ـ ماعت ـ حاب " (شكل 8) (21). وبالنسبة لأجزاء التماثيل السفلية التى عثر عليها فيرث Firth فى الجزء الثمالى الغربى من فناء

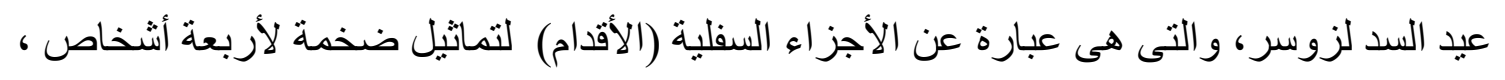

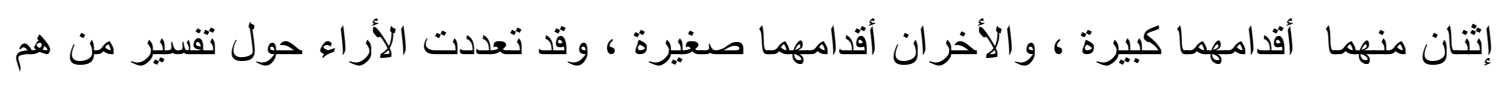

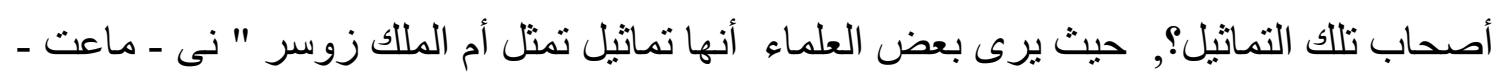

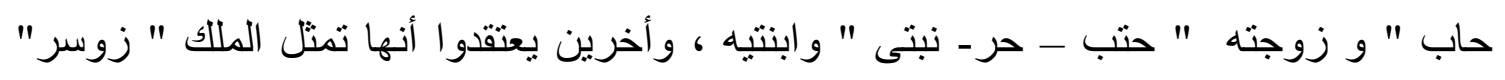

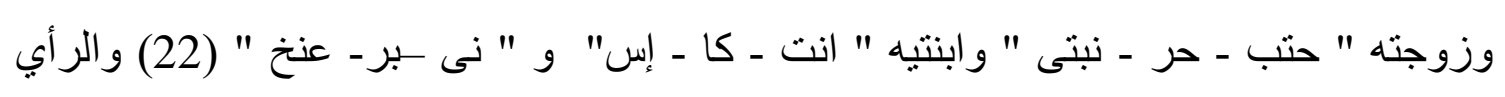

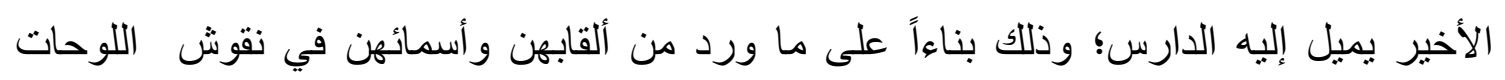

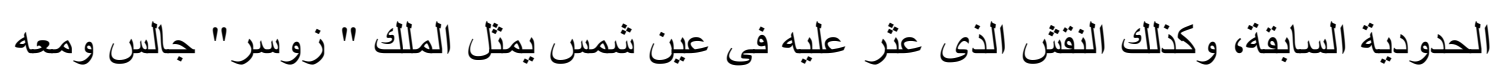

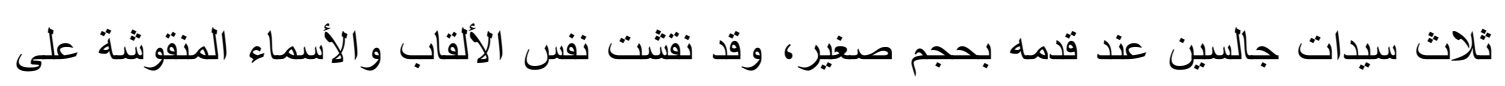

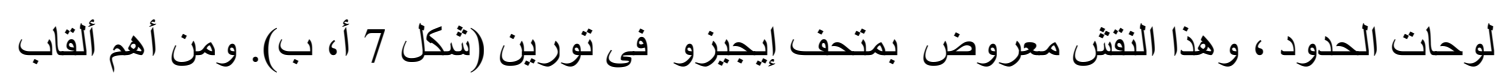

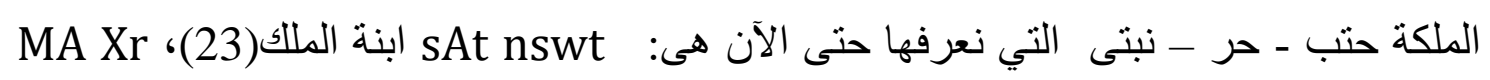
التى ترى حورس . ماسل

أما بالنسبة لمقبرة هذه الملكة : فقد تباينت أراء العلماء فى مكان دفن هذه الملكة ، ويتساءلوا،

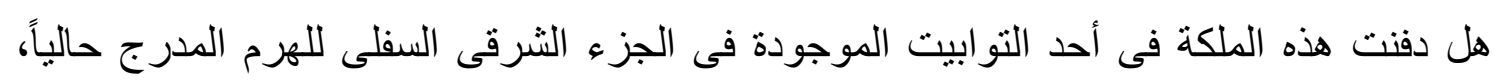

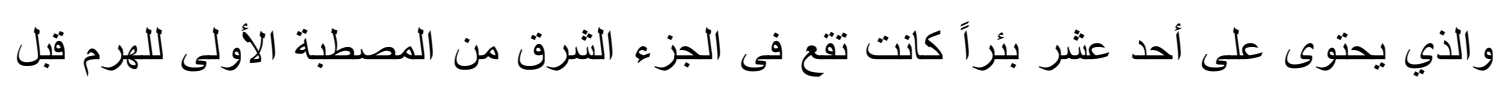

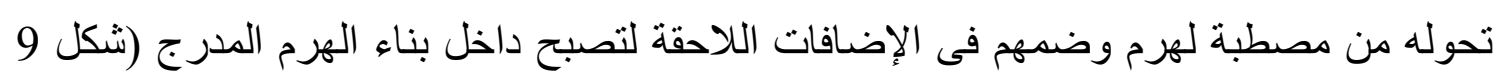

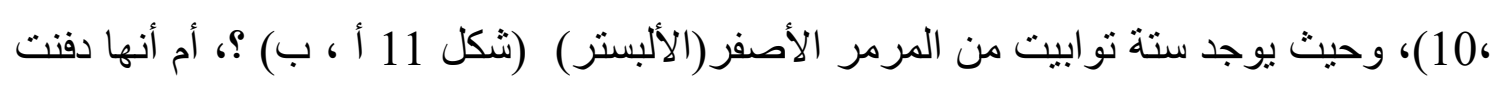

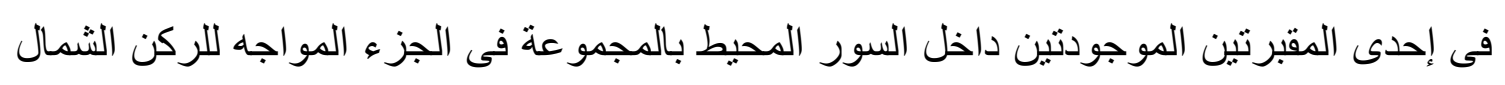

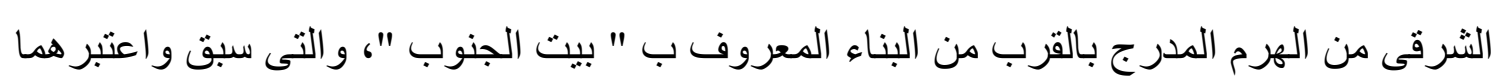

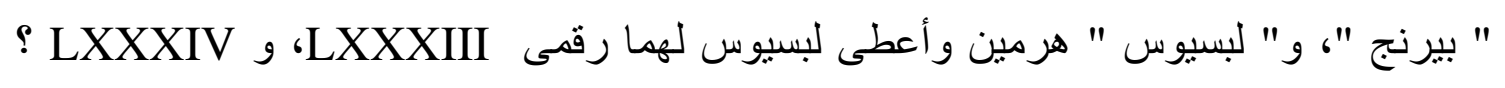

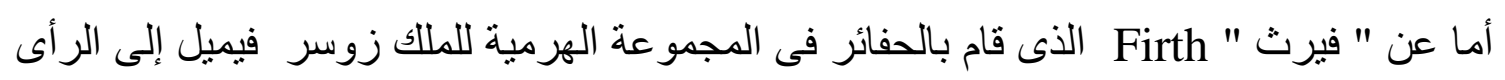

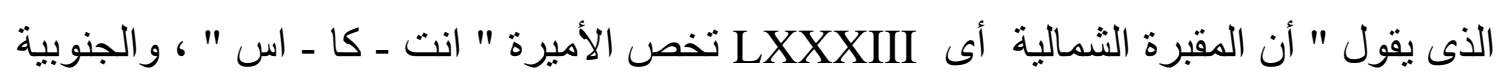
أى LXXXIV تخص الملكة "حتب - حر - نبتى " وذلك لوجود مقصورة جنائزية أمام بئر 
المقبرة LXXXIV مباثرةً، وعثوره على عدد كبير من اللوحات الحدودية لزوسر والمنقوش

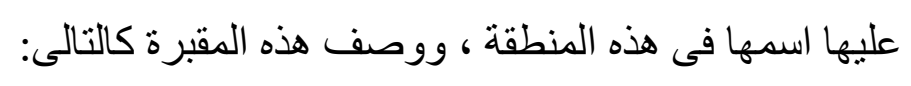

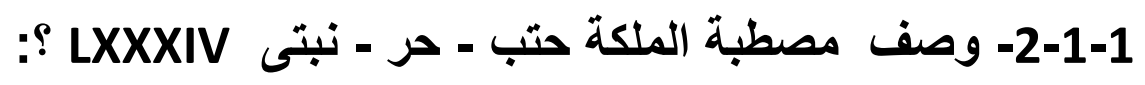

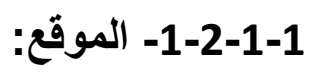

تقع داخل السور المحيط بالمجموعة الهرمية للملك زوسر، في الجزء المواجه للاركن

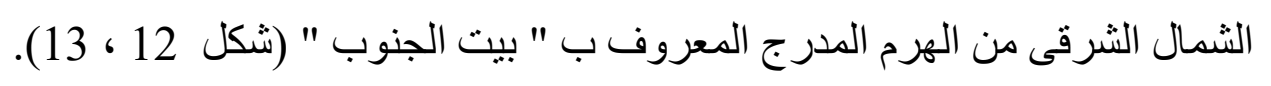

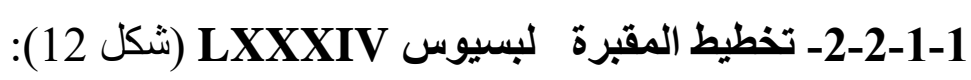

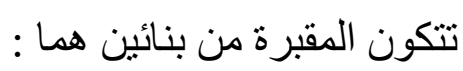

1-2-2-1-1 - البناء السفلى (شكل 14 ، 15):

وهو يتكون من بئر عميق منحوت فى الصخر يصل عمقه حو الى 20 م (24) والجزء العلوى

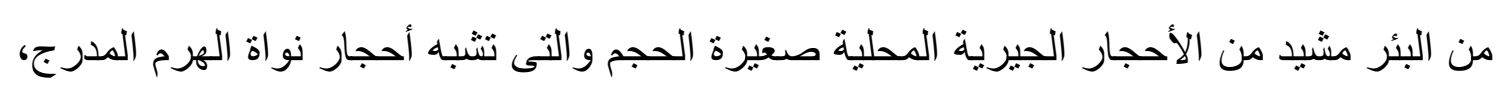

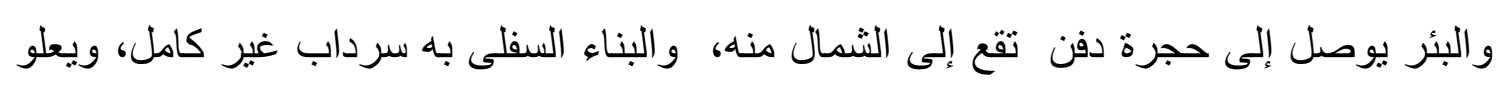
البئر البناء العلوى (25).

\section{2-2-2-1-1 البناء الطوى (شكل 16):}

عبارة عن بناء من كومة من الأحجار الصغيرة المحلية والرمال تعلو البناء السفلى ، وجدرانه

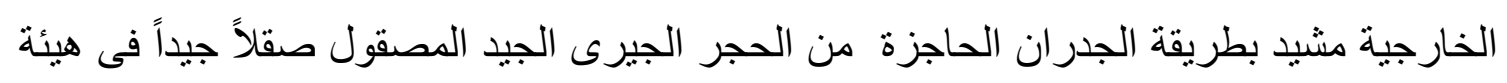

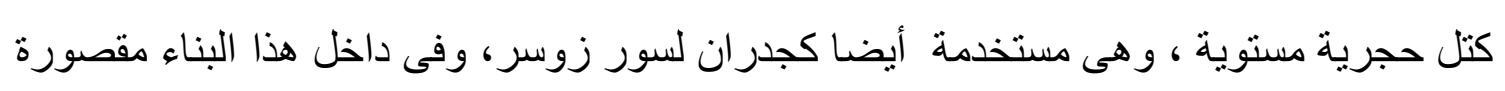
مشيدة من الحجر الجيرى الأبيض الجيد الصقل . 3-2-1-1 المقصورة (شكل 17):

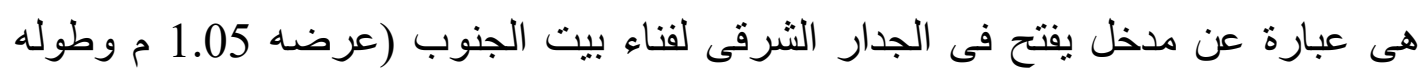

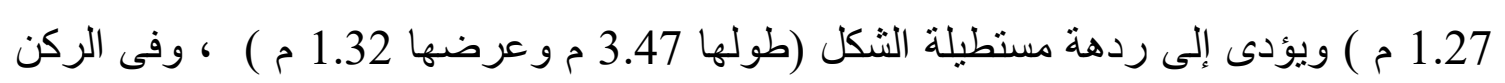

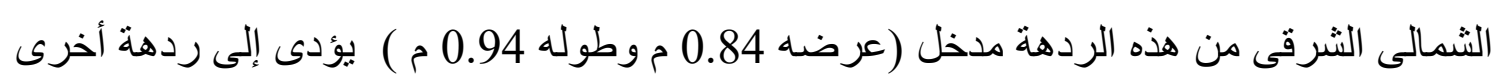

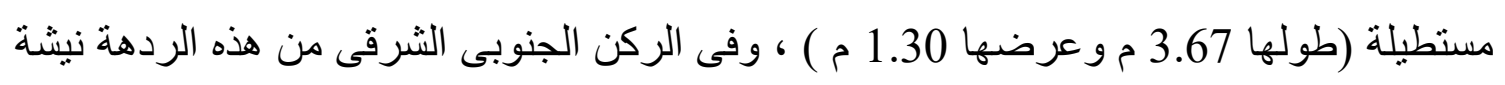

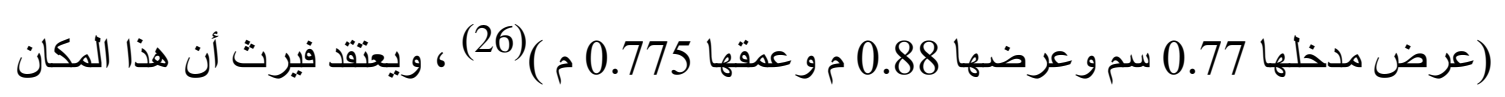


هو المقصورة الخاصة بتقيم القرابين وخاصةً أنه يقع أمام فتحة البئر و أن المقصورة الجنوبية

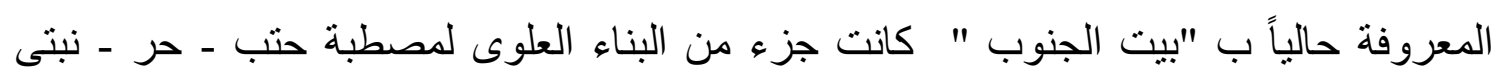
ويعتقد أن سقف هذه المقصورة كان من الحجر الجيرى الملون كتقليد للبراطيم الخشبية ، و النيشة كانت تثبه الناووس (27) أما لوير Lauer فهو يختلف مع رأى " فيرث " Firth ويرى أن مقابر زوجة زوسر وبناته تقع فى داخل الهرم المدرج معلا ذلك بالأتى: 1- إن رأى " فيرث" يستند إلى العثور عدد من اللوحات المعروفة بلوحات الحدود للملك زوسر

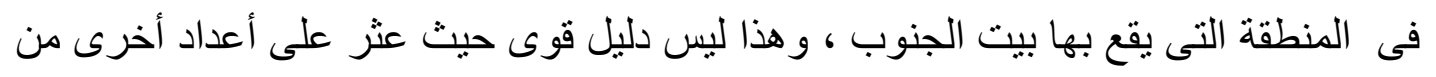

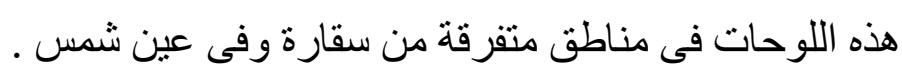

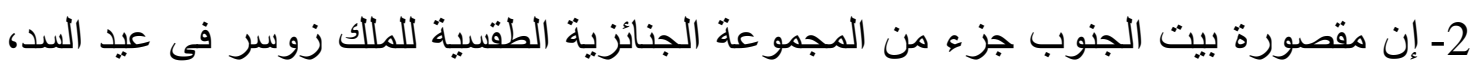

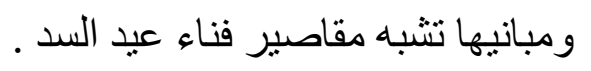

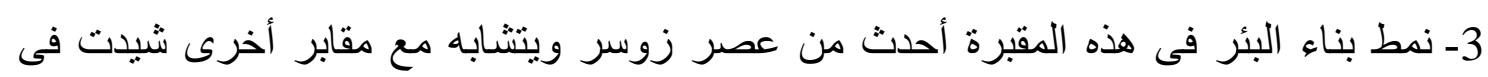

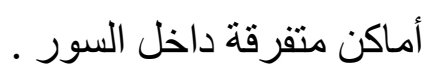

4- وجود زخرفة تيجان البردى على أعمدة بيت الثمال وزخرفة تيجان اللوتس على أعمدة بيت

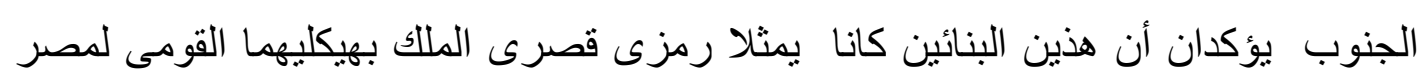
العليا والسفلى (28) - (28) 5- العثور على عظام لسيدة صغيرة العمر أو طفلاً داخل أحد التوابيت الموجود أسفل الهرم المدرج يرحج أن تكون دفنة لإحدى بناته.

ويتفق فيرنر Verner مع لوير Lauer فى أن المقبرة LXXXIV ليست خاصة بالملكة (29) ، ويرى أن أفراد عائلة زوسر تم دفنهم فى الجزء الو اقع به الأحد عشر بئر الو اقعة شرق لهرب

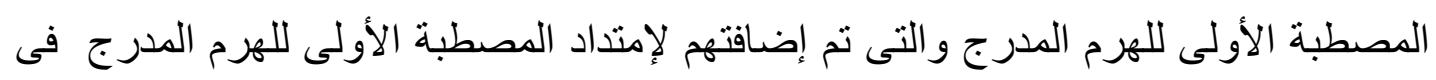

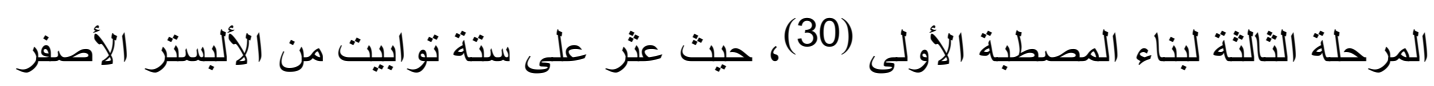
فى مر ات هذا الجزء و التي تقع على عمق 33 م ، و التي تتصل بالممرات المؤدية إلى غرفة

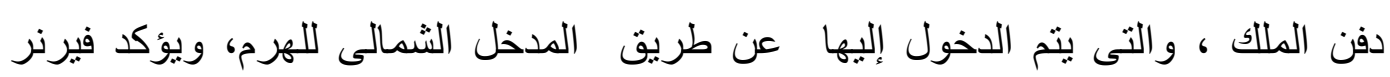
Jerner

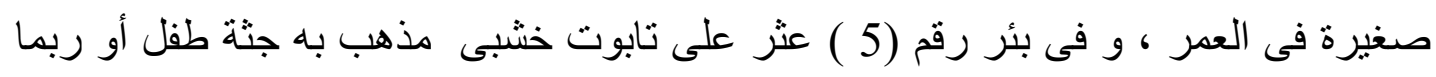

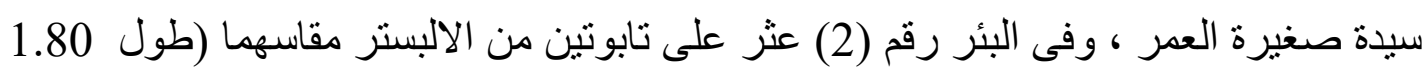


م " وطوله من الداخل 1.57 م ) ، وكان البئر الأخير له حجرة بها متراس من الحجر الجيرى،

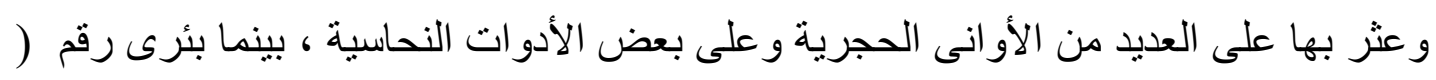
6 ) و (9) عثر بهما على أعداد كبيرة من الأونى الحجرية (31)

أما عبدالعزيز صالح فيرى أن المقابر التى شيدت فى السور المحيط بالمجموعة الجنائزية

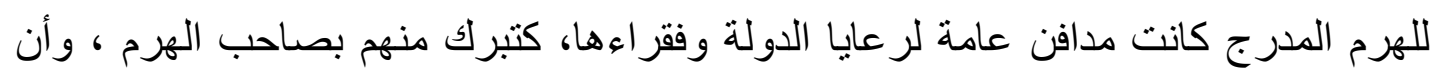

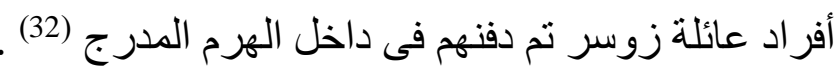

بينما برفض حسن سليم ر رأى فيرث Firth أن بيت الجنوب كان جزءاً من المصطبتين ) مr wr) ، LXXXIV، LXXXIII

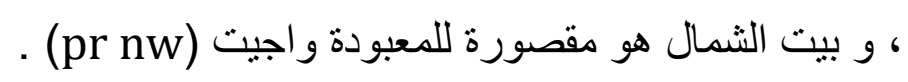

أما الدارس فيميل لرأى فيرث Firth ويعتقد أن مقابر زوجة زوسر وبناته من الدحتمل أن

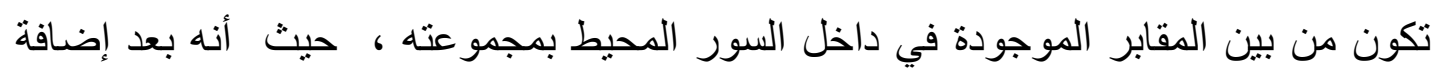

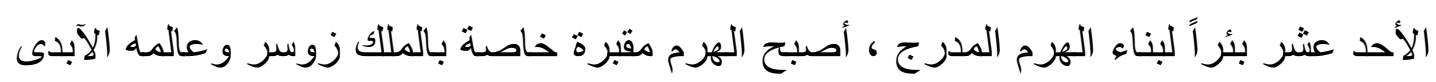

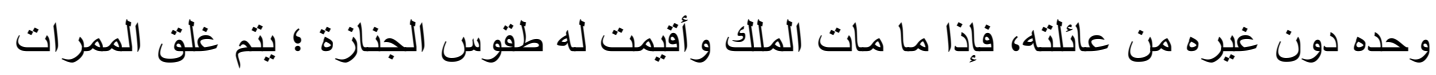

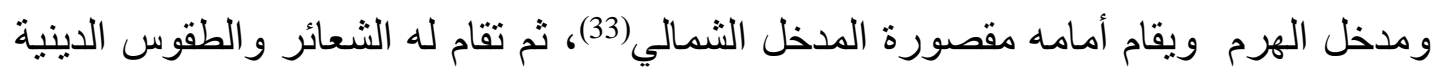

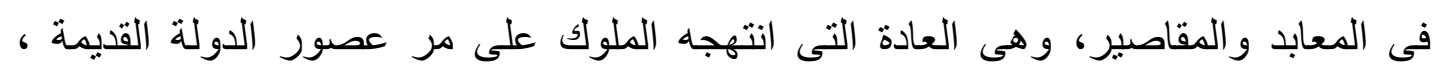

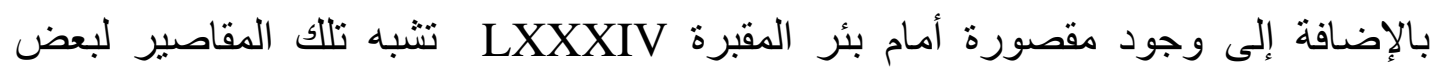

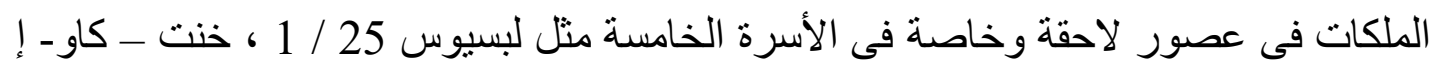

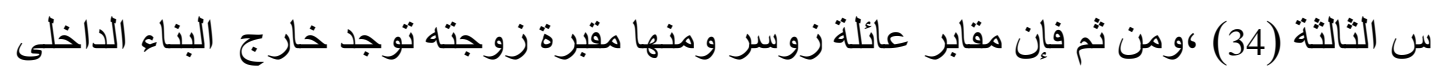

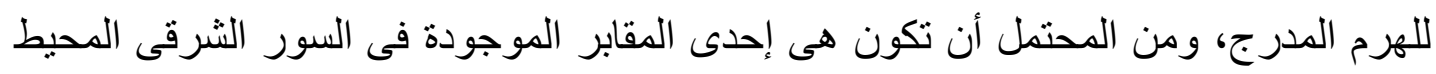

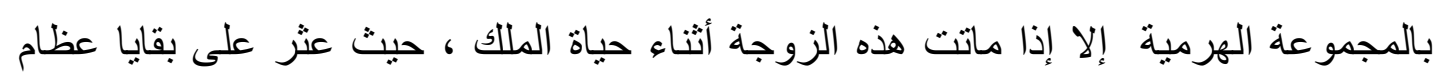

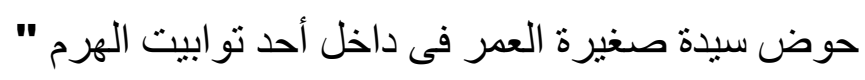

3-1-1- النتائج:

1- من المحتمل أن تكون أحد المقبرتين الموجودتين فى سور زوسر الثرقى بالقرب من بيت

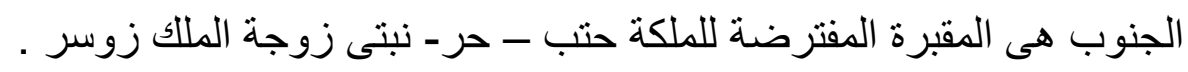
2- تميز البناء السفلى للمقابر فى تنلك الفترة بالبئر العميق . 3- صنعت التوابيت من المرمر الأصفر (الألبستر). 
4- تميزت المقصورة الجنائزية بالبساطة فى التكوين إذا تكونت من ممرين صغيرين يؤديان إلى نبشة صغيرة ربما وضع بها تمثال للملكة.

1- 2- المجموعة الجنائزية للملكة جفات ـ نبتى (ÄfAt - Nbty)

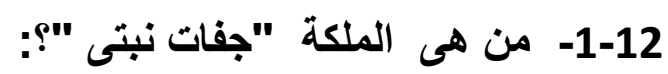

لا نعرف عنها إلا النذر القليل من المعلومات ، وذللك من خلال كسرة إناء من الفخار عثر

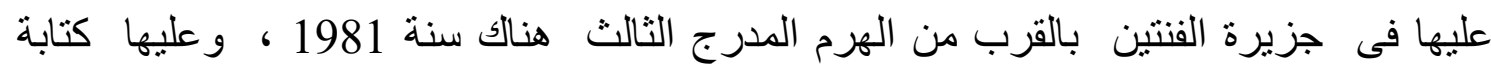
هيرو غيليفية بالمداد الأسود ، ومنها جزء يقر أ " wrt xts ÄfAt - Nbty ..." .... إلى عظيمة صولجان الحتس جفات - نبتى " ، وربما كانت زوجة للملك " حونى " كما يرى دراير Dreyer (شكل 18) (35) حيث أن أسلوب صياغة الكتابة على الإناء تشبه أسلوب صياغة الكتابة على حجر بالرمو؟ (36)، وأما عن مقبرتها فربما تقع فىى المجموعة الجنائزية لزوجها ؟ ، أو هى الهرم

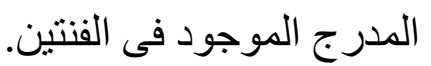

1- 3- مصطبة الملكة مرى - إس - عنخ الأولى ( Mry.s anc )

$$
\text { 1-4-1 من هى الملكة مرى - إس - عنخ الأولى ؟: }
$$

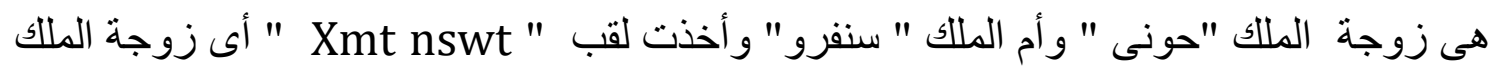

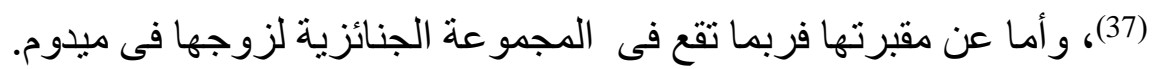
النتائج: 
لقد خلصت در اسة المجمو عات الجنائزية للملكات فى الأسرة الثالثة عن الأتى:

أولاً- شجرة العائلة المحتملة للأسرة الثالثة :

ثانيا ـ أهم المجموعات الجنائزية للملكات فى الأسرة الثالثة:

\begin{tabular}{|c|c|c|c|c|}
\hline العصر & الموقع & طراز المجموعة & الملكة & م \\
\hline زوسر & سقارة & مصطبة & حتب -حر - نبتى & 1 \\
\hline سخم خت & سقارة & $?$ & ملكة ؟ & 2 \\
\hline نب كا سانخت & زواية العريان ؟ & $؟$ & ملكة ؟ & 3 \\
\hline خع با & زواية العريان ؟ & $?$ & ملكة ؟ & 4 \\
\hline حونى ؟ & ميدوم ؟ & $؟$ & جفات - نبتى & 5 \\
\hline حونى & ميدوم & $?$ & مرى- إس- عنخ الأولى & 6 \\
\hline
\end{tabular}

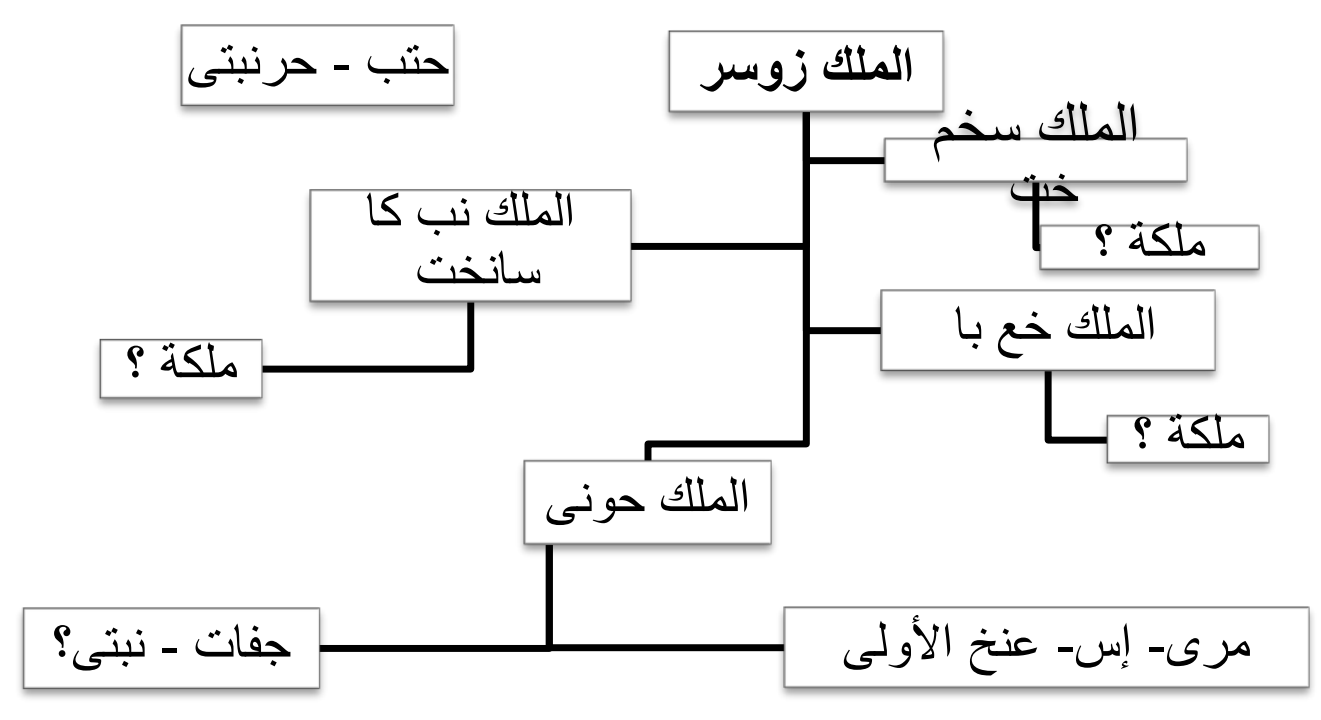

*** ملحوظة : العلامة ؟ و تعنى المعلومة غير مؤكدة أو غير معروفة .

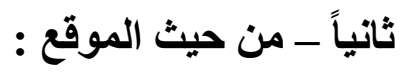


توز عت المجموعات الجنائزية للملكات فى الأسرة الثالثة بين سقارة وزاوية العريان وميدوم ولكن

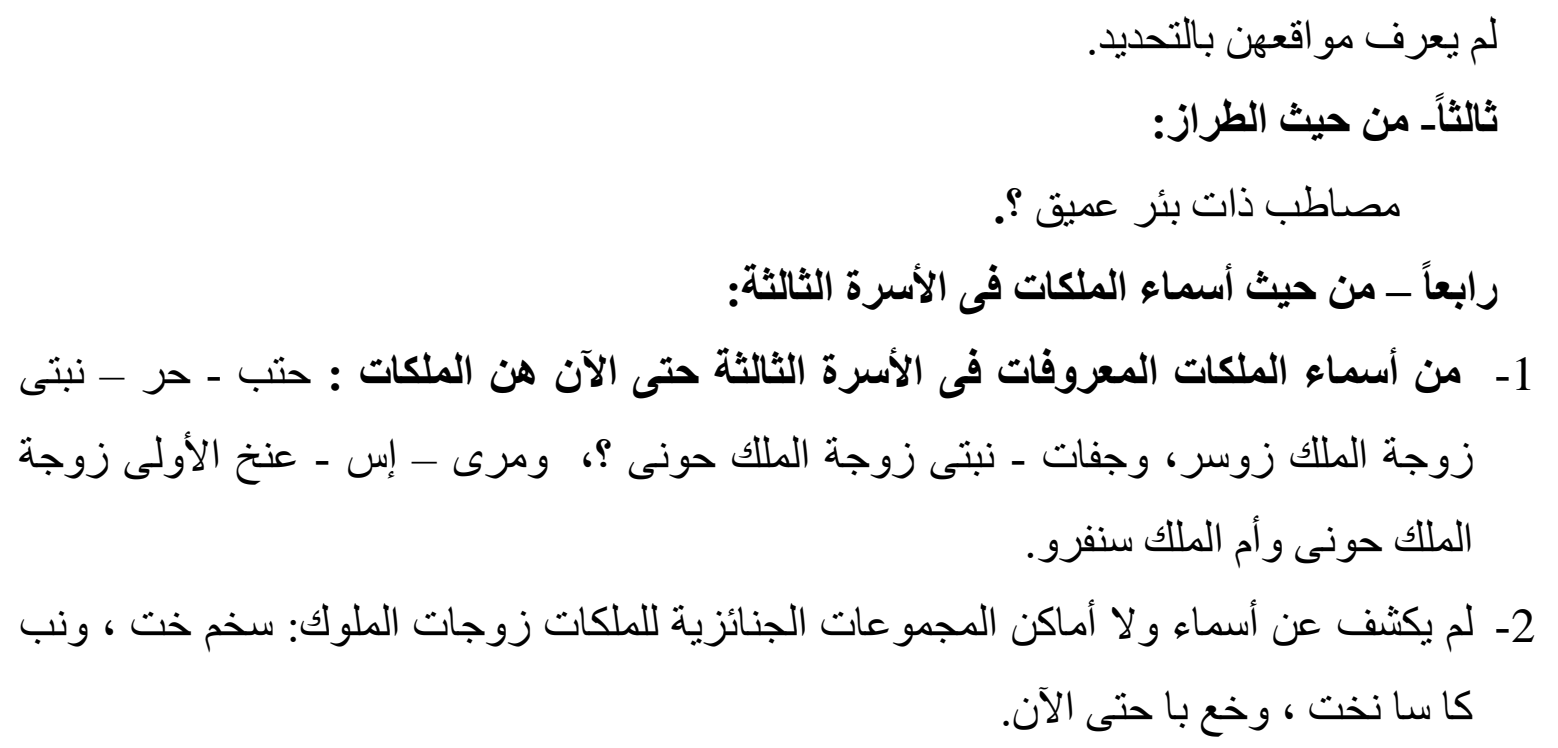

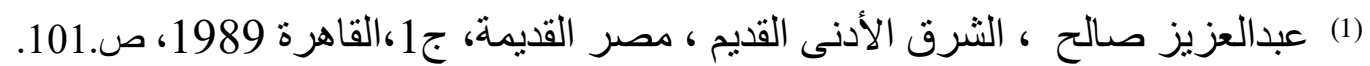

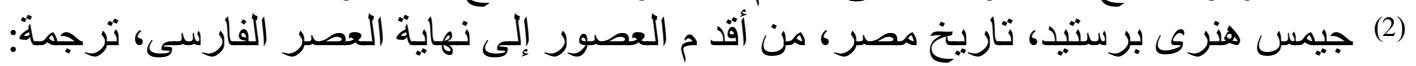

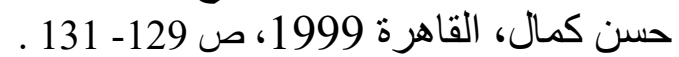

(3) Radwan, A., Step Pyramid, in; Z. Hawass, the Treasures of the pyramids, Cairo 2003, p. 89.

(4) Verner , M.," The pyramids, the mystery, culture and science of Egypt`s great Monuments ", American Uni. Press, Cairo 2002, p. 105.

(5) برستد، جميس هنرى، المرجع السابق، ص. 129.

(6) Firth - Quibell, Step Pyramid I, (1935), p. xxiv.

(7) Von Beckerath, Königsnamen, MÄS 20, München 1984, pp. 48-9.

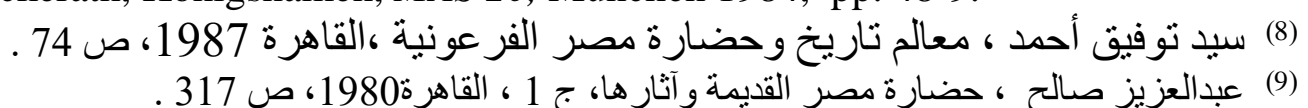

(10) Verner, M., op. cit., pp. 68-73; Marouard, G., Papazian, H., The Edfu pyramid

Project. recent investigation at the last provincial pyramid, oriental institute, Chicago 2012, pp. 3-4.

(11) Elaguizy, O.," Une nouvelle stèle -borne au nom de Djoser ", BIFAO107, ( 2007), pp. 1- 4., fig. 2.

${ }^{(12)}$ http://euler.slu.edu/ bart/egyptianhtml/kings\%20and\%20Queens/Queens_of_Egypt.h tml

${ }^{(13)}$ Troy, L., Patterns of Queenship: in Ancient Egypt Myth and History, Uppsala 1986, p. 153.

(14) Elaguizy, O., op. cit., p. 1.

(15) Firth - Quibell, op. cit., p. 16.

(16) Elaguizy, O., op. cit., p. 1, fig. 2.

(17) Firth - Quibell, op. cit., p. 1, p. 15; idem., Step Pyramid II, pls. 86.5.

(18) Radwan , A., op. cit., p. 86.

(19) Kuraszkiewicz, K. O., "Fragment of the boundary stela of Netjerykhet; Saqqara 2007, in: PAM 19, (2007), pp. 187-8. 


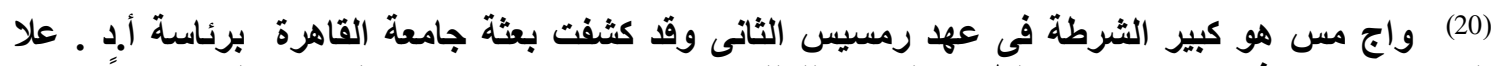

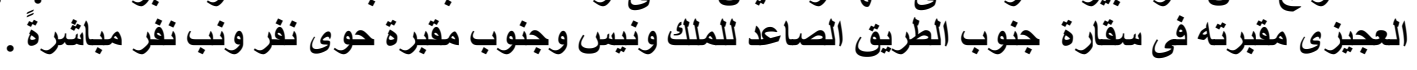

(21) Elaguizy, O., op. cit., pp. 1-4.

(22) Firth - Quibell, Step Pyramid I, p. 16.

(23) Jones, D., An Index of the Ancient Egyptian Titles, Epithets and Phrases of the Old Kingdom, Vol.I,II, Oxford 2000, p. 817, No. 2988.

(24) Lauer, PD II, (1936), p. 134.

(25) Firth - Quibell, op. cit., p. 15.

${ }^{(27)}$ Firth - Quibell, op. cit., pp. 15-6

(26) - مقاسات أخذت بمعرفة الدارس المق

${ }^{(28)}$ Lauer J.-P., La pyramide à Degrés, vol. II, Cairo 1937, pp. 155-6.

(29) Verner, M., op. cit, p. 134.

(30) كرستيان كروش نوبلكور، المر أة الفرعونية ، ترجمة : فاطمة عبد الله محمود، القاهرة 1999،

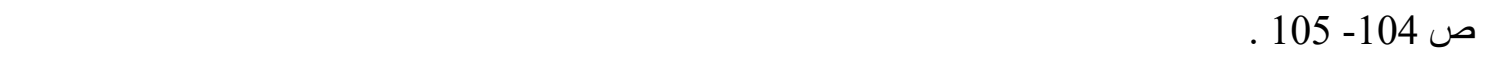

(31) Firth - Quibell, op. cit, pp. 40-41;- Lauer, PD II, pp. 47-50.

(32) عبدالعزيز صالح ، المرجع السابق ، ص.309.

(33) Labrousse, A., Regards sur une Pyramide, (1994), p. 118.

)34( https://www.facebook.com/notes/ministry-of-antiquities- 4/1/2015.

(35) Dreyer, G.," Drei archaisch-hieratische Gefassaufschriften mit Jahresnamen aus

Elephantine", in: Festschrift Fecht, (1987), p. 98, fig. 1.

(36) Strudwick, N., "Texts from the pyramid age", Leiden 2005, p. 74.

(37) Troy, op. cit., p. 153.

Received: April 2021

Accepted: June 2021 